\title{
Myelination and Brain Electrophysiology in Healthy and Schizophrenic Individuals
}

\author{
George Bartzokis*,I \\ 'UCLA Department of Neurology and Greater Los Angeles VA Healthcare System, Los Angeles, CA, USA
}

Neuropsychopharmacology (2003) 28, 1217-1218, advance online publication, 9 April 2003; 10.1038/sj.npp. 1300180

Sir

I am gratified that the 'expanded' neurodevelopmental model of schizophrenia (Bartzokis, 2002) was useful in reinterpreting well-established observations in the field of sleep research and brain electrophysiology. I note that both the paradigm shift on normal brain maturation, which extends well into the fifth decade of life (Bartzokis et al, 2001), as well as the dysregulation of this process in schizophrenia (Bartzokis et al, in press) may prove useful in interpreting age-related as well as disease-related findings in the EEG literature. The synergism provided by the model to the understanding of electrophysiologic manifestations of brain function is to be expected since myelination, the principal process underlying the prolonged human brain maturation, would by its very nature be expected to have an effect on the electromagnetic manifestations of axonal impulse transmission as measured by EEG methods.

The full extent of the synergy offered by the model to understanding normal development and pathophysiology is likely not limited to the field of sleep architecture (Dustman et al, 1996). Certain electrophysiologic approaches that offer more spatial specificity, such as evoked potentials (EP), may offer even greater opportunities for conceptual synergism with this model. Increasing spatial specificity is important because in late adolescence and adulthood, the process of myelination is highly region-specific and occurs primarily in highly 'plastic' association areas (frontal, temporal, and parietal) (Yakovlev and Lecours, 1967; Benes et al, 1994; Bartzokis et al, 2001). In addition, much of the myelination in these regions is intracortical (Kemper, 1994). Thus, the impact of subcortical and intracortical myelination deficits in schizophrenia (Hof et al, 2002) as well as other neuropsychiatric disorders may be best captured through

\footnotetext{
*Correspondence: Dr G Bartzokis, UCLA Alzheimer's Disease Center, 710 Westwood Plaza, Room 2-238, Los Angeles, CA 90095-1769, USA, Tel: + I 310206 3207, Fax: + I 310268 3266,

E-mail: gbar@ucla.edu

Received 3 January 2003; accepted 9 January 2003

Online publication: 3 February 2003 at http://www.acnp.org/citations/ Npp020303008/default.pdf
}

electrophysiologic measures such as EP that are impacted by both subcortical and intracortical changes in myelination.

A quick electronic search of the literature using the most highly replicated abnormalities in EP (P300, P50, and P3) and 'schizophrenia' reveals over 300 citations on this subject. It is exciting to note that recent studies are beginning to explore the question of whether the atypical antipsychotic medications, which may have promyelinating metabolic effects (Bartzokis, 2002), may impact EP abnormalities in schizophrenia (Nieman et al, 2002; Gallinat et al, 2001). The paradigm shift offered by the model of considering myelination as a part of the therapeutic response (or lack thereof), in addition to the usual exclusive focus on receptor effects, may help the field in the effort to unravel the complex and heterogeneous syndrome we call schizophrenia. Further synergism can be expected if neurocognitive, electrophysiologic, neuroimaging, and genetic technologies are simultaneously brought to bear in conceptual models that bring focus to the often ignored lifelong process of brain development and the multiple clinical manifestations dysregulations of this process may have (Bartzokis, 2002).

\section{REFERENCES}

Bartzokis G (2002). Schizophrenia: breakdown in the well regulated lifelong process of brain development and maturation. Neuropsychopharmacology 27: 672-683.

Bartzokis G, Beckson M, Lu PH, Nuechterlein K, Edwards N, Mintz $\mathrm{J}$ (2001). Age-related changes in frontal and temporal lobe volumes in men: a magnetic resonance imaging study. Arch Gen Psychiatry 58: 461-465.

Bartzokis G, Nuechterlein KH, Lu PH, Gitlin M, Rogers S, Mintz J (in press). Dysregulated brain development in adult men with schizophrenia: a magnetic resonance imaging study. Biol Psychiatry.

Benes FM, Turtle M, Khan Y, Farol P (1994). Myelination of a key relay zone in the hippocampal formation occurs in the human brain during childhood, adolescence, and adulthood. Arch Gen Psychiatry 51: 477-484. 
Dustman RE, Emmerson RY, Shearer DE (1996). Life span changes in electrophysiological measures of inhibition. Brain Cognition 30: 109-126.

Gallinat J, Riedel M, Juckel G, Sokullu S, Frodl T, Moukhtieva R et al (2001). P300 and symptom improvement in schizophrenia. Psychopharmacology 158: 55-65.

Hof PR, Haroutunian V, Copland C, Davis KL, Buxbaum JD (2002). Molecular and cellular evidence of an oligodendrocyte abnormality in schizopohrenia. Neurochem Res 27: $1193-1200$.
Kemper T (1994). Neuroanatomical and neuropathological changes during aging and dementia. 2nd edn. Oxford University Press: New York.

Nieman DH, Koelman JHTM, Linszen DH, Bour LJ, Dingemans PM, Ongerboer de Visser BW (2002). Clinical and neuropsychological correlates of the P300 in schizophrenia. Schizophr Res 55: 105-113.

Yakovlev PI, Lecours AR (1967). In: Minkowski A (ed). Regional Development of the Brain in Early Life. Blackwell Scientific Publications: Boston. pp 3-70. 